\title{
Green chemistry and textile industry
}

\begin{abstract}
Contrary to non-sustainable, non-renewable fossil fuel-based conventional chemical processes, green reactions are sustainable, highly efficient (fewer steps, fewer resources, less waste), much easy-to-use (stable under ambient conditions) and very much eco-friendly (non-hazardous solvents and less hazardous minimized waste). They are assessed by twelve principles. The textile industry is considered as ecologically one of the most polluting industries in the world. Recently a number of steps have been taken to make textile processing greener. These include use of greener fiber, greener dyes and auxiliaries, greener solvents, eco-friendly, optimized and efficient processing, bio-processing, recycling of textile, water and chemicals and elimination of hazardous chemicals.
\end{abstract}

Keywords: green chemistry, textile fibres, textile dyeing, textile finishing, ionic liquids
Volume 2 Issue 3 - 2017

\author{
Asim Kumar Roy Choudhury \\ KPS Institute of Polytechnic, India \\ Correspondence: Asim Kumar Roy Choudhury, Principal \\ in KPS Institute of Polytechnic, Retired Professor and HOD \\ (Textile) in Govt College of Engineering \& Textile Technology, \\ Serampore, Hooghly (WB) India, Residence: USHAJIT,Arabinda \\ park, PO Belu-Milki- 7|2223, Hooghly (WB), India, \\ Email akrc2008@yahoo.in
}

Received: August 18, 2016 | Published: July 14, 2017

\section{Introduction}

For ages, biochemical processes by nature evolve elements that are abundant and close at hand-such as carbon, hydrogen, oxygen, nitrogen, sulfur, calcium and iron. Industries, in contrast, gather elements from nearly every corner of the planet and distribute them in ways natural processes never could. Lead, for example, used to be found mostly in deposits so isolated and remote that nature never unfolded it into living organisms. But now lead is everywhere, primarily because our paints, cars and computers have spread it around. Some of the new synthetic molecules in medicines, plastics and pesticides are so different from the products of natural chemistry as if they are dropped in from an alien world. ${ }^{1}$

Two basic types of materials are available in nature are:

a. Renewable materials which grow, get biodegraded and re-grow,

b. Non-renewable finite materials which do not grow and may exhaust if used intensively.

Unsustainable conventional chemical manufacturing processes depend on non-renewable carbon-based fossil fuels (petroleum and coal) and generate large amounts of waste polluting the environment.

\section{Non-eco-friendly substances}

The terms environmentally friendly, eco-friendly, nature friendly, and green are used to refer to goods and services, laws, guidelines and policies claimed to inflict minimal or no harm on the environment Webster. $^{2}$ The companies sometimes use eco-labels to promote marketing of environmental friendly goods and services.

The following categories of substances are considered as non-ecofriendly:
i. Non-biodegradable organic materials,
ii. Hazardous substances,
iii. Accident prone substances.

i. Non-biodegradable organic materials: Non-biodegradable material is a substance that is not broken down by microbes and has an oxygen demand only if it is a chemical reducing agent. It has no biochemical oxygen demand Goel. ${ }^{3}$ ii. Hazardous chemicals: According to American Occupational Safety and Health Administration, a highly hazardous chemical is a substance that is both toxic and reactive and whose potential for human injury is high if released. Highly hazardous chemicals may cause cancer, birth defects, genetic damage, miscarriage, injury and death from relatively small exposures. Hazardous substances may be classified into two groups on the basis of toxicity namely:

\section{A.Toxic heavy metals \\ B. Volatile organic solvents}

A. Toxic metals/heavy metals: Heavy metals are defined as metals which have a large atomic number. They have specific gravity 4-5 times greater than that of water and usually belong to atomic number of 22-34 and 40-52 and members of lanthanides and actinides of the periodic table Landage. ${ }^{4}$ Biologically, the heavy metals denote certain category of metals which are most harmful ecologically. They may enter the body through food, water or air or by absorption through skin and tend to bio-accumulate. Many of them form lipid soluble organo-metallic compounds that accumulate within the cells and organs impairing their functions. Some heavy metals and associated health hazards are listed below:

a. Lead $(\mathrm{Pb})$ : damage to brain, nervous system and kidneys. In mild cases, cause insomnia, restlessness, loss of appetite and gastrointestinal problems.

b. Mercury (Hg): damage to brain.

c. Cadmium (Cd): disorders of respiratory system, kidneys and lungs;

d. Chromium (Cr): skin and respiratory disorders, ulceration of skin, cancer of respiratory tract on inhalation.

e. Arsenic (As): skin cancer, hyper-pigmentation, kurtosis and black foot disease.

Some of the heavy metals commonly exist in textile effluent are arsenic, cadmium, chromium, cobalt, copper, lead, manganese, mercury, nickel, silver, tin, titanium and zinc. Among the possible sources of heavy metals in textile operations are incoming fiber, 
water, dyes, auxiliaries, finishing, plumbing and chemical impurities Panov et al. ${ }^{5}$

Pollution created by contamination of natural waters and soil by toxic heavy metals is still an environmental problem. Heavy metals enter the environment with wastewaters from different branches of industry, in particular, from discharged spinning baths, from chemical fiber plants, discharged effluent from dyeing machines, from chemical plant wastes, from electroplating shops in machine-building factories, etc. A significant amount of heavy metals enters the environment in cities from vehicle emissions. Solid industrial wastes also contribute to the environmental pollution by heavy metals Phipps. ${ }^{6}$

B. Volatile organic solvents: Volatile organic compounds (VOCs) are organic chemicals that have high vapour pressure at ordinary, room-temperature conditions (e.g. benzene, toluene, acetone, ethyl alcohol, per (or tetra) chloroethene (PERC), trichloroethene (TCE) etc.). Their high vapour pressure results from their low boiling points causing large numbers of molecules to evaporate from the liquid or solid form of the compound and enter the surrounding air. An example is formaldehyde, with a boiling point of $-19^{\circ} \mathrm{C}\left(-2^{\circ} \mathrm{F}\right)$ slowly exits into the air, unless kept in a close container.

Many VOCs are dangerous to human health or cause harm to the environment. VOCs are numerous, varied, and ubiquitous. They include both man-made and naturally occurring chemical compounds. Anthropogenic VOCs are regulated by law, especially indoors, where concentrations are the highest. VOCs are typically not acutely toxic, but instead have compounding long-term health effects. Because the concentrations are usually low and the symptoms slow to develop, the researches about VOCs and their effects are difficult. Respiratory, allergic, or immune effects in infants or children are associated with man-made VOCs and other indoor or outdoor air pollutants Bernstein et al. ${ }^{7}$ VOCs may cause several health disorders namely eye, nose, and throat irritation, headaches, loss of coordination, nausea, damage to liver, kidney, and central nervous system. Some VOCs can cause cancer in animals; some are suspected or known to cause cancer in humans.

\section{Green chemistry}

'Green Chemistry' is essentially a way of thinking rather than a new branch of chemistry and is about utilizing a set of principles that seek to reduce the adverse environmental impact of chemical processes and products and to contribute to sustainable development. ${ }^{8}$

Environmental chemistry studies the effect of environmental pollutants, whereas green chemistry deals with new sciences and technologies to prevent the formation of any waste by life cycle assessment (LCA). The principles of green chemistry offer an upstream solution to many of the health, environmental, and economic problems spawned by industrial chemicals Dawson. ${ }^{9}$

The green issues are being confused with 'organic' sourcing and production. Indeed, many people are unaware that some of the most known toxic chemicals (for example, Ricin and Botulin) are not manufactured but are natural proteins. ${ }^{10}$

\section{Life cycle assessment}

A life cycle assessment (LCA), life cycle analysis, eco-balance or cradle-to-grave analysis is a technique to assess environmental impacts associated with all the stages of a product's life cycle (i.e., from raw material extraction through materials processing, manufacture, distribution, use, repair and maintenance, and disposal or recycling). ${ }^{11}$

LCA is a holistic environmental assessment tool that addresses raw material use and emissions in all processes in the product chain from raw material extraction through production, use and final disposal. The environmental impact of a substance i emitted to the environment from a process is calculated as follows in Equation 1.

$$
E P(j)_{i}=Q_{i} x E F(j)_{i}
$$

Where $Q_{i}$ : is the emitted quantity of substance i

$\mathrm{J}$ : the environmental impact (for example, global warming)

I: $\mathrm{CO}_{2}, \mathrm{CO}, \mathrm{CH}_{4}, \mathrm{~N}_{2} \mathrm{O}, \mathrm{NO}_{3}, \mathrm{PO}_{4}, \mathrm{SO}_{2}$, etc

EF: an effect factor

The environmental impact potential of a product is given by the Equation 2:12

$$
E P(j)_{\text {product }}=\sum\left(Q_{i} x E F(j)_{i}\right)
$$

LCAs enable a manufacturer to quantify how much energy and raw materials are used, and how much solid, liquid and gaseous waste is generated, at each stage of the product's life. LCAs might be conducted by an industry sector to enable it to identify areas where improvements can be made, in environmental terms. A report by Cotton incorporated ${ }^{13}$ contains data on land, water and energy use, greenhouse gas emissions and ecosystem services for cotton production in the United States. This self-evaluation of impact of production on the environment conducted by Cotton Incorporated forms the basis of a life cycle inventory (LCI) of the agricultural production of cotton, a prerequisite for conducting the more comprehensive life cycle analysis (LCA) of a cotton product.

\section{Principles of green chemistry}

Green chemistry recommends Clark ${ }^{14}$ use of the reactions with the following objectives:

i. Elimination or minimization of waste.

ii. No or fewer wastage of atom (atom economy).

iii. Catalysts are preferred to stoichiometric reagents, which are used in excess and work only once.

iv. Direct reactions with minimum or fewer steps. The derivatives or intermediate steps use additional reagents and generate waste.

v. Use of fully effective, yet safer and non-toxic products

vi. Safe chemical synthesis routes.

vii. Renewable and not depleting feedstock.

viii. Easy and harmlessly degradable chemicals - no accumulation in the environment.

ix. No solvent or safer solvents and reaction conditions.

$\mathrm{x}$. Energy efficient processes preferably at ambient temperature and pressure reactions.

xi. Real-time monitoring and control of by-products. 
xii. Avoiding hazardous chemicals - no changes of explosions, fires and harmful releases.

\section{Advantages of green reactions}

The advantages of adopting green chemistry Matus ${ }^{15}$ are:

a. Green Chemistry assures a series of reductions leading to economic, environmental, and social improvements.

b. Cost saving by

i. Reducing waste and its disposal costs (especially for hazardous waste),

ii. Reducing energy consumption (lowering process costs),

iii. Reducing materials consumption due to more efficient processes.

c. These reductions also lead to environmental benefit in terms of both feedstock consumption and end-of-life disposal.

d. An increasing use of renewable resources rendering sustainable manufacturing industry.

e. The reduction in hazardous incidents and the handling of dangerous substances provides additional social benefit-not only to plant operators but also to local communities and to the users of chemical-related products.

\section{Implementation of green reactions}

For about twenty years, green chemistry produced a number of noteworthy successes across a number of sectors, which have served as examples to the larger chemical community. Yet for all of the movement on the scientific front, and for all of the truly innovative work done by some firms, green chemistry has yet to become a fundamental operating strategy in the majority of chemical firms. Six major classes of barriers to the implementation of green chemistry are Poliakoff \& Licence: ${ }^{16}$

i. Economic and financial: occasionally Green Chemistry is more expensive than conventional routes and the future benefits are uncertain.

ii. Regulatory: emphasis is on exposure reduction and not on hazard reduction; lack of global harmonization on regulation and environmental policy; insufficient funding for research and regulatory incentives for greener alternatives.

iii. Technical: non-availability of suitable substitute reactions and solvent systems; non-availability of trained chemists and engineers; poor knowledge about existing green products and processes and non-sharing of relevant information among industries.

iv. Organizational: problems arise from intra-organizational conflicts, lack of support at executive or technical level and lack of understanding in sales and marketing.

v. Cultural: poor awareness and wrong conception about efficiency and cost of green reactions among consumers and general public.

vi. Definition and metrics: poor guidance on best practice and sufficient teaching on sustainable chemistry; difficulty in measuring greenness of a reaction and in conducting multi-dimensional optimization.

\section{Challenges for green chemistry}

The challenges for green chemistry are the identification of the following:

a. Renewable feedstock, preferably non-food plants and their full conversion to useful products,

b. Reactions having minimum environmental impact, for example, use of eco-friendly organic catalysts.

c. Industrial processes and reactors having maximum efficiency and minimum waste,

d. Products of reduced toxicity and increased biodegradability to substitute environmentally harmful chemicals.

e. Prediction of chemical and biological properties of compounds from their chemical structures.

f. Cleaner solvents as replacements of the flammable, toxic and volatile solvents polluting atmosphere.

\section{Focus areas}

Sustainable (green) chemistry technologies can be categorized into the following three focus areas:

A. Alternative synthesis routes,

B. Alternative reaction conditions, and

C. Alternative chemicals - safer, less toxic or less accident prone.

Catalysis not only helps to make chemical processes greener (for example, by replacing reagents or by enabling more efficient processes) but also to reduce the environmental impact and the costs of the processes. Heterogeneous catalysts and reagents may be chosen so that they can easily be separated (and reused) at the end of a process.

Every Green Chemistry textbook describes the big successes of the last decades in the field of new synthetic routes for industrial chemicals. The first is the synthesis of Ibuprofen; the second is the synthesis of adipic acid (important starting chemical substance for Nylon and catehole and the third is the synthesis of Maleic anhydrite (starting material for polyesters and dyes).

Adipic acid is a very important starting material for Nylon-6,6 and catehole (which is used in the pharmaceutical and pesticide industries). Adipic acid is produced annually in more than 2.000 millionkg. In the past, the industrial production of adipic acid used benzene as a starting material.

Benzene is one of the basic chemicals for industrial reactions and a solvent. It is derived mainly from the refining processes of the petrochemical industry. Benzene is also known for its carcinogenic properties (it causes leukemia to highly exposed workers). Afterwards the starting material became cyclohexanone or a mixture of cyclohexanone and cyclohexanol. For the oxidation process nitric acid is used, producing toxic fumes of nitric oxides, NOx, which are also contributors to the greenhouse effect and the destruction of the ozone layer in the stratosphere.

The "old", traditional method for the manufacture of adipic acid is the oxidation of cyclohexanone/cyclohexanol by nitric acid in the presence of catalyst copper/vanadium $[\mathrm{Cu}(0.1-05 \%)$ and $\mathrm{V}(0.02-$ $0.1 \%)]$ the reaction is: 
$\mathrm{C}_{6} \mathrm{H}_{12} \mathrm{O}+2 \mathrm{HNO}_{3}+\mathrm{H}_{2} \mathrm{O} \rightarrow \mathrm{C}_{6} \mathrm{H}_{10} \mathrm{O}_{4}+\mathrm{NO}_{x}\left(\mathrm{NO}, \mathrm{NO}_{2}, \mathrm{~N}_{2} \mathrm{O}, \mathrm{N}_{2}\right)$

It was inevitable that the method had to be changed again with more environmentally benign reactions. . Finally, chemical engineers and synthetic organic chemists researched for alternatives. The "greener" method of manufacturing of adipic acid uses a new generation of catalysts. The starting chemical is cyclohexene and its oxidation is performed by $30 \%$ hydrogen peroxide $\left(\mathrm{H}_{2} \mathrm{O}_{2}\right)$. The catalyst is dissolved in a special organic solvent (Aliquat 336). The catalyst is a salt of the metal Volfram or Tungsten (W) (Tungsten catalysts $\left(\mathrm{Na}_{2} \mathrm{WO}_{4} / \mathrm{KHSO}_{4} /\right.$ Aliquat 336) (Figure 1).

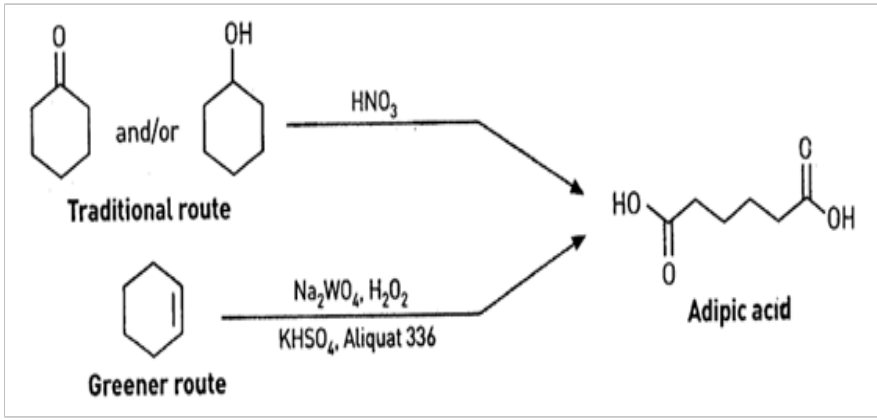

Figure I Tungsten catalysts $\left(\mathrm{Na}_{2} \mathrm{WO}_{4} / \mathrm{KHSO}_{4} /\right.$ Aliquat 336).

Other scientists promoted the biocatalytic method of synthetic adipic acid from D-glucose. It is achieved with genetically transgenic bacteria Klebsiella pneumoniae, a non-toxic strain of Escherichia coli, (Enterobactiriaceae).The scientist who researched and applied the new biocatalytic synthesis of adipic acid was awarded the "Presidential Green Chemistry Challenge Awards Program" in 1998 in the USA.

The "old" Method for Synthesis of maleic anhydrite used benzene $\left(\mathrm{C}_{6} \mathrm{H}_{6}\right)$ as a starting material and a catalyst which was composed of oxides of Vanadium and Molybdenum, $\mathrm{V}_{2} \mathrm{O}_{5}$ and $\mathrm{MoO}_{3}$ (fixed bed reactor)

$$
2 \mathrm{C}_{6} \mathrm{H}_{6}+9 \mathrm{O}_{2}(\text { air }) \rightarrow \text { catalysts } \rightarrow 2 \mathrm{C}_{4} \mathrm{H}_{2} \mathrm{O}_{3}+\mathrm{H}_{2} \mathrm{O}+4 \mathrm{CO}_{2}
$$

The "new greener" method with starting material n-butane and catalyst $(\mathrm{VO})_{2} \mathrm{P}_{2} \mathrm{O}_{5}$ (fixed bed reactor)

$$
C_{4} \mathrm{H}_{10}+3.5 \mathrm{O}_{2}(\text { air }) \rightarrow \text { catalyst } \rightarrow \mathrm{C}_{4} \mathrm{H}_{2} \mathrm{O}_{3}+4 \mathrm{H}_{2} \mathrm{O}
$$

\section{Evaluation of green reactions}

Reaction mass efficiency takes into account atom economy, chemical yield and stoichiometry. Like carbon efficiency, this measure shows the "cleanness" of a reaction but not of a process. These metrics can present a rearrangement as "very green" but they would fail to address any solvent, work-up and energy issues arising from the practical reaction. For a generic reaction where $A+B \rightarrow C$, simply, Reaction mass efficiency $=$ mass of product $C \times 100 /$ (mass of $\mathrm{A}+$ mass of B). For synthesis of maleic anhydrite described above, the reaction mass efficiency is $57.6 \%$ in the new method while the same for the traditional method is $44.4 \%$.

In an ideal chemical process, the amounts of starting materials or reactants are equal to the amount of all products generated and no atom is wasted. Atom economy is the molecular weight of desired product expressed as percentage of total molecular weight of all reactants. The masses of the atoms of all starting materials and reagents according to the stoichiometric equation are added and are compared with the sum of the masses of all atoms found in the desired product. Atoms of undesired side products and reaction by-products are counted as waste. The concept was introduced by Tros ${ }^{17}$ Atom economy can be poor even when chemical yield is near $100 \%$.

The concept of atom economy can be illustrated in general by the reaction shown in Equation 7.

$$
(\text { reagent })_{1}+\ldots .+(\text { reagent })_{n} \rightarrow \text { product }+ \text { byproduct }
$$

The ultimate in atom economy is achieved when there is no byproduct and all the reagents are contained within the product. Although this is often not achievable in practice, it is desirable to devise reaction schemes such that

$$
\text { byproduct }<<\text { product }
$$

A high degree of atom economy assures high efficiency of a chemical reaction. Addition reactions show better atom economy than condensation or substitution reactions, which generate stoichiometric amounts of unwanted products.

While atom economy focuses on the reaction only, Sheldon factor of environmental acceptability, E factor, assesses how green is a chemical process by measuring the amount of waste generated as a ratio of the mass of waste to that of the product Sheldon. ${ }^{18}$ For truly green processes, the E factor should be zero. Large-scale manufacturing units for bulk chemicals may generate large amount of waste, but their E factors may be smaller than those of smallscale units as it depends on the quantity of waste in relation to total production. Table 1 shows environmental acceptability (E factor) of some established chemical production processes Ali. ${ }^{19}$

Table I Environmental Acceptability (E Factor) of Various Industries

\begin{tabular}{ll}
\hline Industrial chemical process & E factor \\
\hline Oil refining & 0.1 \\
Commodity chemicals & $<1.5$ \\
Special chemicals & May-50 \\
Drugs & $25->100$ \\
\hline
\end{tabular}

\section{Traditional vs green solvents}

The conventional solvents represent a great challenge to green chemistry because of their toxicity and flammability Manahan. ${ }^{20}$ Benzene causes blood disorders and is suspected of causing leukemia. Di methyl nitrosamine, one of the $\mathrm{N}$-nitroso $(\mathrm{N}-\mathrm{N}=\mathrm{O})$ compounds, was once widely used as an industrial solvent, but caused liver damage and jaundice in exposed workers. Carbon tetrachloride causes lipid peroxidation in the body and severe damage to the liver and also causes stratospheric ozone destruction. In 1996, estimated atmospheric emissions of carbon tetrachloride were 41,000 metric tonnes. As production of chlorofluorocarbons (CFCs) is phased out under the Montreal Protocol, carbon tetrachloride emissions will continue to decline Jessop. ${ }^{21}$

\section{Ionic liquids}

Ionic liquids (ILs) are liquids composed entirely of ions. Thus, 
molten sodium chloride is an ionic liquid while a solution of sodium chloride in water (a molecular solvent) is an ionic solution. Regardless of whether polar or non-polar, the common solvents (for example, water, ethanol and benzene) are generally molecular liquids. ILs are basically constituted of ions and when they are used as solvents, they behave differently from molecular liquids. The majority of them consist of nitrogen-containing organic cations and inorganic anions. The most commonly studied systems contain phosphonium, imidazolinium or tricaprylmethyl ammonium cations, with varying heteroatom functionality.

ILs are considered green (environmentally benign) reaction media. They can contribute significantly to sustainable chemistry and the development of green technology. Unfortunately, ILs does have disadvantages. Some of them are more toxic than others. Their preparation from raw materials can be energetically and economically expensive, and separation of ILs from solutes (without using traditional solvents) can be problematic.

\section{Green chemicals}

The green chemicals should meet the following criteria:

a. Prepared from renewable or readily available resources by environmentally friendly processes,

b. Low tendency to undergo sudden, violent, unpredictable reactions such as explosions,

c. Non-flammable or poorly flammable,

d. Low toxicity and absence of toxic constituents, particularly heavy metals,

e. Biodegradable,

f. Low tendency to undergo bioaccumulation in food chains in the environment.

Several laboratory chemicals are controversial from the perspective of Green chemistry. The Massachusetts Institute of Technology has green chemical alternative wizard to identify alternatives. It is a webbased tool that is designed to provide chemical alternatives to some of the most commonly used hazardous solvents and substances in research laboratories. The Green Chemical Alternatives Wizard provides over 200 journal references and case studies that detail alternative chemicals and/or processes available for hazardous solvents, reagents, and cleaning agents. Ethidium bromide, xylene, mercury, and formaldehyde have been identified as "worst offenders" which have alternatives. Solvents in particular make a large contribution to the environmental impact of chemical manufacturing and there is a growing focus on introducing Greener solvents into the earliest stage of development of these processes: laboratory-scale reaction and purification methods. In the Pharmaceutical Industry, both GSK and Pfizer have published Solvent Selection Guides for their Drug Discovery chemists.

Among many possible sources of heavy metals in textile operations are incoming fibre, water, dyestuffs (heavy metals are constituents of some classes of dyes and pigments), auxiliaries, finishing, chemical impurities and the plumbing fittings used in dyeing and finishing plants; heavy metals may also be found in plant fibres due to absorption from the soil in which they are grown. Once absorbed by humans, heavy metals tend to accumulate in internal organs such as the liver or kidney with serious effects on health, particularly when high levels of accumulation are reached. For example, high levels of lead can seriously affect the nervous system.

Both cadmium and lead are classified as carcinogens. Cadmium has been restricted in Europe for a long time. Cadmium and cadmium oxide were classified as carcinogens and aquatic acute and chronic toxic. Since 31 December 1992, cadmium has been prohibited under the Council Directive 76/769/EEC of European Union (Regulation Concerning the Registration, Evaluation, Authorization and Restriction of Chemicals, henceforth REACH). Lead is restricted in the United States under the Consumer Product Safety Improvement Act (CPSIA) and children's products that contain more lead than 600ppm have been banned in the United States since 10 February 2009, whilst the permissible lead content in paint and similar surface-coating materials for consumer use is reduced from $600 \mathrm{ppm}$ to $90 \mathrm{ppm}$; there are similar European regulations controlling the content. Chromium (VI) is an undesirable by-product generated during the leather-tanning process, whenever chrome tanning is employed. Chromium (VI) is a strong oxidant and a skin irritant and is classified as a carcinogen that needs to be controlled [150]. Nickel is found in alloys used for metal accessories on garments such as buttons, zippers and rivets. Some people are allergic to nickel and may experience serious skin irritation when come in contact with nickel-containing accessories for an extended period. The release of nickel is restricted under the EU REACH Regulation (EC) No 1907/2006, Annex XVII.

\section{Greener energy}

Sustainable energy is energy that is consumed at insignificant rates compared to its supply and with manageable collateral effects, especially environmental effects. Another common definition of sustainable energy is an energy system that serves the needs of the present without compromising the ability of future generations to meet their needs. The organizing principle for sustainability is sustainable development, which includes the four interconnected domains: ecology, economics, politics and culture.

Sustainability science is the study of sustainable development and environmental science. Technologies promote sustainable energy including renewable energy sources, such as hydroelectricity, solar energy, wind energy, wave power, geothermal energy, bio energy, tidal power and also technologies designed to improve energy efficiency. Costs have fallen dramatically in recent years, and continue to fall. Most of these technologies are either economically competitive or close to being so. Increasingly, effective government policies support investor confidence and these markets are expanding. Considerable progress is being made in the energy transition from fossil fuels to ecologically sustainable systems, to the point where many studies support $100 \%$ renewable energy.

Green energy comes from natural sources such as sunlight, wind, rain, tides, plants, algae and geothermal heat. These energy resources are renewable, meaning they're naturally replenished. In contrast, fossil fuels are a finite resource that take millions of years to develop and will continue to diminish with use.

The processes like heating, cooling, stirring, distillation, compression, pumping and separation require electrical energy which is obtained by burning of fossil fuel. This results in release of carbon dioxide in the atmosphere causing global warming. Green chemistry aims at developing alternative energy generation such as photovoltaic, 
hydrogen, fuel cells and bio- based fuels. Energy efficiency can be improved by catalytic green reactions and by improved product design.

The fuels obtained from renewable feed-stocks are more acceptable. Bio-diesel is produced from oils of cultivated plants like soya-beans. It is synthesized from fats embedded in plant oils by removing the glycerine molecule - a valuable raw material for soap production. The combustion of bio-diesel does not generate sulfur compounds and generally does not increase the amount of carbon dioxide in the atmosphere.

Biomass, a renewable energy source, is biological material from living, or recently living organisms, such as wood, forest residues for example (such as dead trees, branches and tree stumps), waste, (hydrogen) gas, and alcohol fuels. Biomass is commonly plant matter grown to generate electricity or produce heat. There is a renewed interest in the use of biomass for production of fuels and of basic chemicals and solvents.

\section{Textile industry and sustainability}

The following five issues make the life cycles of textiles and clothing unsustainable Teli: ${ }^{22}$

I. Chemicals - as many as 2,000 different chemicals are used in the textile industry, from dyes to transfer agents; and

II. Water - the textile industry is the highest consumer and polluter of clean water (after agriculture). Water is used at every step of the textile process both to convey the chemicals used during the step and to wash them out before beginning the next step. The treated water is discharged as wastewater polluting the environment by increasing heat, changing $\mathrm{pH}$ (acidic or alkaline) and contaminating with considerable quantities of chemicals like dyes, de-foamers, bleaches, detergents, optical brighteners, dyeing and printing auxiliaries and many other chemicals used during the process.

III. Energy - textile production and textile consumer consume a large quantity of non-renewable energy sources in the form of electricity to heat water for running laundry and to dry materials after laundering. For textile industry, data on energy usage are relatively readily available. The complication arises while estimating the associated $\mathrm{CO}_{2}$ emissions that arise from the sources (coal, electricity, natural gas or other sources) from which the energy is produced. The output of $\mathrm{CO}_{2}$ depends heavily on the source of energy. The use of electricity is associated with in-buiIt inefficiencies as compared to the direct use of thermal energy. Even steam is less efficient energy source than direct-fired gas heating in a mill.

IV. Waste - textile industry generates a huge quantity of waste. For greener processes, non-renewable wastes are to be recycled and renewable are to be composted as much as possible.

V. Transportation - Excessive consumption of non-renewable fuel in transportation as the labor-intensive textile production units is generally far away from consumer point to utilize cheap labor and land.

The sustainability of textile products is further tarnished when packed with huge quantity of plastics and layers of foam. Sustainability can be improved by the use of recyclable and reusable packaging materials.
Traditionally, the fabrics contain residuals of chemicals used during their manufacture. Volatile chemicals evaporate into the air we breathe or are absorbed through our skin. Some of the chemicals are carcinogenic or may cause harm to children even before birth, while others may trigger allergic reactions in some people. It is estimated that the population that is allergic to chemicals will grow to 60percent by the year $2020 .{ }^{23}$

\section{Bio-polymers}

The term "biopolymers" implies that they are bio-based or/and biodegradable. Where "biological" means (recently) produced by living organisms, i.e. not produced from petroleum. Biopolymers may be thermoplastic or thermoset, they can be composites or homogeneous and they can be biodegradable or not. Biopolymers often have a well defined structure, though this is not a defining characteristic (example: ligno-cellulose)

It is desirable to make polymers from renewable biological sources and to synthesize and use polymers that will biodegrade after disposal. The use of biopolymers, i.e. plastics made from corn, sugar, starch and other renewable raw materials, has exploded in recent years.

Polylactic acid or poly lactide (PLA) (Figure 2a) is thermoplastic aliphatic polyester derived from renewable resources, such as corn starch (in the United States), tapioca products (roots, chips or starch mostly in Asia) or sugarcanes (in the rest of world). It can biodegrade under certain conditions, such as the presence of oxygen, and is difficult to recycle.

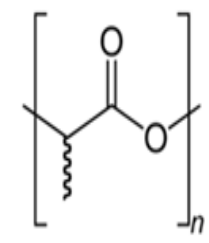

(a)

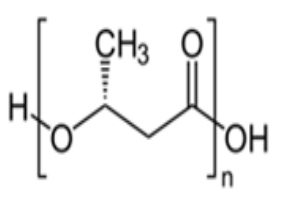

(b)

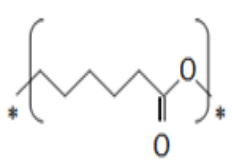

(c)
Figure 2 Chemical Structures of Biopolymers (a) polylactic acid (b) Poly(R)-3-hydroxybutyrate (P3HB) (c) polycaprolactone.

The medical applications of this polymer arise from its biocompatibility. The fibers may be fabricated into various forms and may be used for implants and other surgical applications such as sutures. Tissue engineering is the most recent domain where poly lactic acid is being used and is found to be one of the most favourable matrix materials.

Classification: Biopolymer groups and the corresponding members are as under:

a. Polyester: Poly hydroxy alkanoates (PHA), poly lactic acid

b. Polysaccharides (plant/algal): Starch (amylase/amylopectin), cellulose, agar, alginate, carrageenan, pectin, various gums (e.g. guar)

c. Polysaccharides (bacterial): Xanthan, dextran, levan, poly galatosamine, cellulose (bacterial)

d. Polysaccharides (animal): chitin/chitosan, hyaluronic acid

e. Polysaccharides (fungal): pullulan, elsinan, yeast glucans

f. Protein: silk, collagen/gelatine, adhesives, polyamino acid, soy, zein, wheat gluten, casein, serum albumin 
g. Lipids/surfactants; acetoglycerides, waxes

h. Poly phenols: Lignin, tannin, humic acid

i. Specialty polymers: Shellac, natural rubber, synthetic polymers from natural fats and oils (e.g. nylon from castor oil).

\section{Advantages of biopolymers}

i. They are fully bio based.

ii. Much lower "oil (petroleum)" is needed for production

iii. Lower amount of green house gases emits during their production. Ingeo ${ }^{\circledR}$ (Polylactic acid or PLA from Nature works) requires $60 \%$ less greenhouse gases and $50 \%$ less non-renewable energy than other polymers (Ditty, 2013).

\section{Disadvantages of biopolymers}

i. The competition for biological sources of food and fuel

ii. Additional sorting during recycling to avoid contamination.

iii. Performance still inferior to oil based polymers-poorer heat and moisture resistance.

The name poly lactic acid is to be used with caution as it does not comply with standard nomenclatures (such as IUPAC) and potentially leading to ambiguity that PLA is not polyacid (polyelectrolyte), but rather polyester.

Cargill Dow's wonderful and well-known technology uses corn to produce polylactic acid (PLA). This marvelous process consumes up to $50 \%$ less fossil fuel than the conventional PLA manufacturing processes using petroleum-based feed-stocks. The commercial viability of the polymer relies on novel processing that can be used to manipulate the molecular weight, crystallinity and chain branching, enabling materials with a wide range of end users and markets to be made. PLA has high strength, good drape, and wrinkle and UV lightresistance properties. The route of manufacture is as follows Reddy \& Yang: ${ }^{24}$

Corn $\rightarrow$ starch $\rightarrow$ unrefined dextrose $\rightarrow$ fermentation $\rightarrow$ D- and L-lactic acid $\rightarrow$ monomer production $\rightarrow$ D-, L- and meso-lactides $\rightarrow$ polymer (PLA) production $\rightarrow$ polymer modification $\rightarrow$ fiber, film, plastic, bottle etc. The polymerization reaction is shown in Figure 3.

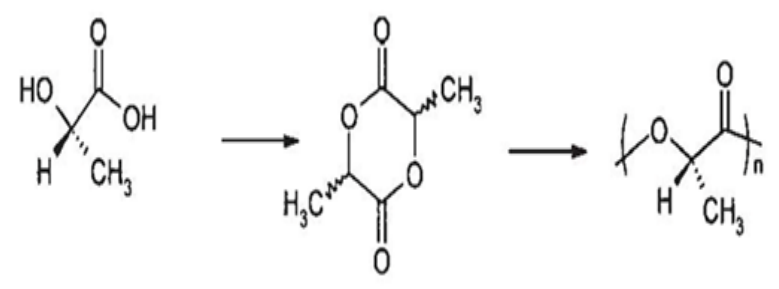

Figure 3 The polymerization reaction.

The process produces no toxic wastes, and its end products are fully biodegradable (into lactic acid and carbon dioxide) and compostable, since they degrade within 45-60 days. They have, therefore, lower environmental impact. The several benefits of corn fibres are expected to make these fibers preferable over the currently available natural and man-made fibers.

The most active current area of research in natural polymers involves bacterial polyesters poly hydroxy alkanoates (PHAs) with Poly-(R)-3-hydroxybutyrate (P3HB) as the first homologue (Figure 2b). These polymers were found to be produced by fluorescent Pseudomonads and other bacteria which generate and store them as reserves of carbon and energy. Their production has now been achieved in transgenic (genetically engineered) plants. Advantages include production from fully renewable resources, fast and complete biodegradable, excellent strength and stiffness, which favours this material as a polymer for future. However, serious drawbacks of these polymers include highly thermal degradability and brittleness with consequent difficulty in processing, and high price Grose. ${ }^{25}$

Polycaprolactone (Figure 2c) is a synthetic polymer prepared by ring opening polymerisation of caprolactone. The mechanical properties are similar to polyolefins. It is similar to PHAs and fully biodegradable, but degrades at a lower rate compared to PHAs. Due to lower melting temperature of about $60^{\circ} \mathrm{C}$, the polymer is mainly used in polymer blend or as a matrix for biodegradable composites.

\section{Greener fibres}

Cotton represents almost $38 \%$ of the world's textile consumption, second only to polyester. It is highly susceptible to pests, especially in humid areas. Though cotton production is restricted to $2.4 \%$ of cultivable land globally, an estimated $25 \%$ of global insecticide and $11 \%$ of global pesticide are consumed in cotton cultivation. This 'thirsty' crop also requires 7000-29000liters of water to produce one $\mathrm{kg}$ of cotton fibre Grose. ${ }^{25}$

Organic cotton is generally obtained from a non-geneticallymodified plant that is certified to be grown without the use of any synthetic fertilizers or pesticides. Similarly, 'organic linen' refers to linen that is made from flax fibres grown without the use of toxic pesticides and fertilizers.

The preparatory processes required before dyeing and printing are similar for organic and conventional processing. However, some chemicals such as substances with high AOX (adsorbable organic halogens) values, bluing agents, chelating agents, chlorine compounds, formaldehyde etc. are prohibited to use for organic textiles. All dyes should conform to ETAD $^{26}$ restriction regarding residual heavy metals and banned aromatic amines. The first choice for dyeing organic fabric, where, applicable, could be plant-based natural vegetable dyes. However, their commercial availability is limited. The best choice could be low-impact dyes made from petrochemicals such as fibre reactive dyes. Permitted synthetic and non-synthetic chemicals are listed in eco-labels like Global Organic Textile Standard (GOTS). The use of synthetic fire retardants and many functional finishes are prohibited. Mechanical finishing techniques must be explored instead of chemical finishes wherever possible.

Although wool itself is a natural fibre, traditionally wool is not produced in eco-friendly way. Organic wool ensures that the wool has been produced in a much more natural and sustainable way, compared to non-organic wool.

Organic certification standards are different among various countries. In some countries, the standards are set and overseen by the government. In other countries, the standards are set by a non-profit organization or even by private companies.

Regenerated cellulose fibres namely rayons are manufactured by dissolving cellulose in conventional solvents followed by precipitation in suitable solution (mostly mineral acids). Both carbon disulphide and cuprammonium hydroxide are used for dissolving cellulose, but they cause environmental problems. Hence, attempts have been made to develop an alternate process. Lyocell fibres are 
produced by regenerating cellulose in an organic solvent, N-methyl morpholine-N-oxide (NMMO) hydrate. Non-toxic, biodegradable NMMO solvent is almost completely recycled Albrecht et al. ${ }^{11}$ The lifecycle of a lyocell fibre has minimal environmental impact. The fibre is significantly more sustainable than oil-derived synthetic fibres (e.g. polyester, nylon, and acrylic) and natural fibres such as cotton. The cultivation of cotton requires significant areas of land, irrigation, pesticides and fertilizers to grow as compared to eucalyptus trees, from which lyocell is made. Lyocell fibres are available in the market in the name of Tencel (Courtaulds, USA), Lyo Cell (Lenzig, Austria), and New Cell (Akzo-Nobel, Germany).

\section{Recycled textiles}

After use, much of the painfully achieved textile products are thrown away, buried or burned. By recycling, companies can realize larger profits because they avoid charges associated with damping in landfills, while at the same time contributing to goodwill associated with environmentalism, employment for marginally employable workers, donation to charities and disaster relief and the movement of used clothing to areas of the world where clothing is needed. The textiles being nearly $100 \%$ recyclable, nothing in textile and apparel industry should be wasted. The textile recycling industry is one of the oldest and most established recycling industries in the world. Textile recycling materials may be pre-consumer or post consumer (i.e. used garments or articles). The sorting categories of textile recycling by volume is represented by a pyramid structure, the base of which consists of used cloth market (48\%), followed by conversion to value added new materials (29\%), cut into wiping and polishing cloths $(17 \%)$ and landfill and incineration for energy $(<7 \%)$. The peak of the pyramid is represented by 'Diamonds' (1-2\%) which have high value for antique quality or for other reason Hawley. ${ }^{27}$

Polyester fibre is one of the most non-biodegradable polymers which create environmental problems. There are two broad types of recycled polyester in the market namely:

a. Simply melted and re-extruded into fibres and

b. A multi-stage de-polymerization and re-polymerization to produce better quality yarn.

\section{Greener colorants}

Azo groups $(-\mathrm{N}=\mathrm{N}-)$ are not available in nature. Azo groups incorporated in benzenoids form the basis of majority of synthetic dyes. Approximately $70 \%$ of all dyes (belonging to various dyeclasses) used in textile industries are azo dyes.

It has been estimated that less than $4 \%$ of known azo dye structures would release the corresponding amines. Under reductive conditions using sodium dithionite these azo groups may be cleaved to form two amines as shown in Equation 9.

$$
A-N=N-B \frac{\mathrm{Na}_{2} \mathrm{~S}_{2} \mathrm{O}_{4}}{\mathrm{pH} 6} \mathrm{~A}-\mathrm{NH}_{2}+\mathrm{B}-\mathrm{NH}_{2}
$$

A small number of the aromatic amines are classified as being carcinogenic or potentially carcinogenic to humans. Only a few azo dyes can release these amines upon reductive cleavage. The regulation, EU Directive 2002/61/EC identified twenty two aromatic amines as harmful and has prohibited their use.

Figure 4 shows chemical structures of four amines which are definitely carcinogenic.

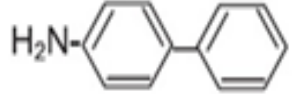

(a)

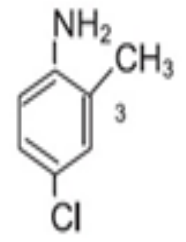

(c)

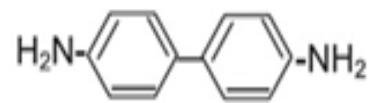

(b)

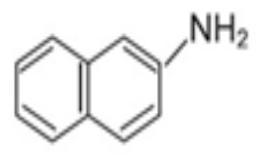

(d)
Figure 4 Chemical structure of four carcinogenic amines: (a) 4-aminodiphenyl; (b) benzidine; (c) 4-chloro-o-toluidine; and (d) 2-naphthylamine

\section{Greener auxiliaries}

Some of the harmful textile chemicals and their eco-friendly substitutes are shown in Table 2.

\section{Greener preparatory processes}

Textile materials possess a variety of impurities. Some are natural or inheriting and others may be added purposefully for better textile manufacturing or contaminated accidentally. All such impurities are to be removed before actual dyeing or printing processes. The steps by which the impurities are removed are called preparatory processes, which may vary from fibre to fibre. They may be broadly classified into two groups, namely:

i. Cleaning processes namely singeing (removal of projected fibres), desizing (removal of starch and other sizes applied on yarns) and scouring (removal of bulk impurities),

ii. Bleaching or destruction of coloring matters.

iii. The most important application of green chemistry is the use of enzymes in textile preparatory processes. The enzymes are applied in various stages of textile processing namely desizing, scouring, bleaching, dyeing, finishing and composting.

\section{Modification of dyeing processes}

Dyeing is a process of uniform coloration of textile materials using dyes or pigments in aqueous medium. The process demands the use of a large number of chemicals including acid or alkali. This is generally conducted at high temperature for prolonged time.

The following are some of the process modifications for making dyeing processes greener:

a. Process optimization to reduce process time and energy consumption.

b. Reduced consumption of water (ultra low liquor ratio dyeing-3:1 to $4: 1$ for polyester and 6:1 for cotton), electrical power and steam consumption in general.

c. Substitution of hazardous sodium sulphide with sustainable, nontoxic, biodegradable, cost-effective reducing sugars in sulphur dyeing.

d. The dyeing of cationized cotton with reactive dyes with low or no salt and alkali addition. 
e. Polyester is mostly dyed in costly pressurized dyeing machines. Economy can be achieved by reducing dyeing time using selected low molecular weight disperse dyes (to avoid unlevel dyeing at faster rate of dyeing) and optimized design of dyeing machines.

f. Minimize reprocessing and shade correction. Acceptable shade at first attempt is called Right-First-Time dyeing, no addition dyeing or blind dyeing. Twenty factors which must be monitored or controlled to achieve RFT processing in the dyeing process have been identified (Park and Shore, 2004). Continual refinement of textile machine design and its control equipment, together with dye selection and reliable recipe prediction systems in the laboratory have contributed to a high proportion of

Table 2 Harmful textile chemicals and their eco-friendly substitutes

\begin{tabular}{|c|c|}
\hline Existing chemicals & Uses \\
\hline Polyvinyl alcohol (PVA) & Yarn size \\
\hline Pentachlorophenol, formaldehyde & Size preservative \\
\hline Carbon tetrachloride (CTC) & stain removers \\
\hline Calcium and sodium hypochlorite & Bleaching \\
\hline Sodium silicate, phosphorous-based compounds & Peroxide stabiliser \\
\hline Nonyl phenyl ethylene oxide adducts (APEO) & Detergent, emulsifier \\
\hline Synthetic non-biodegradable surfactants & Various purposes \\
\hline $\begin{array}{l}\text { Synthetic non-biodegradable surfactants + } \\
\text { solvent }\end{array}$ & Coatings and degreasing \\
\hline Dichloro and trichloro benzene & Carriers in dyeing \\
\hline Kerosene & Pigment printing \\
\hline Formaldehyde & Finishing, dye fixing \\
\hline Sodium dichromate & Oxidation in dyeing \\
\hline Silicones and amino-silicones+APEO emulsifier & Softener \\
\hline Functional synthetic finish & Finishing \\
\hline
\end{tabular}

\section{New greener coloration processes}

Savings of energy, water and chemicals: The savings can be achieved by adopting following means:

a. Continuous preparatory and dyeing methods instead of batch wise methods minimizing consumption of the energy, water and chemical to less than half.

b. Semi-continuous cold pad-batch dyeing processes with reactive dyes instead of batch wise or pad-steam methods.

c. Chemical-free water-free denim processing using laser technology to burn away quickly the surface of the dyed denim fabric or a pair of jeans on a mannequin to replicate an authentic worn look. Conventionally, this is done with stones, oxidizing agent or enzymes by aqueous methods. right first time dyeing Goel. ${ }^{3}$

g. Multiple savings are possible through automation in textile dyeing and printing such as Park..$^{28,29}$

i. Process control- $10-30 \%$ saving in water and energy as well as $5-15 \%$ saving in dyes and chemicals.

ii. Auto-dispensing- 5-10\% savings in dyes, pigments and chemicals.

iii. Computer-controlled weighing and stock-taking- 10-15\% savings in dyes, pigments and chemicals.

iv. Color measurement and matching-significant improvement in quality and $30-40 \%$ savings of dyes and pigments. 
on supercritical carbon dioxide $\left(\mathrm{scCO}_{2}\right)$ as dyeing medium has been received from researchers. This is apparent from the fact that 143 articles on the topic have been reviewed by Manahan. ${ }^{20}$ However, it has not been commercialized yet. Carbon dioxide combines a relatively mild critical point with non-flammability, non-toxicity and a low price. Because of its green and safe character, it is the best supercritical solvent for textile dyeing. It is obtained as waste product of combustion, fermentation and ammonia synthesis and need not to be produced especially for dyeing.

The carbon dioxide and the residual dye (after dyeing) can be easily separated by depressurization and both the compounds can be recycled. No waste is generated. The energy-intensive drying after dyeing is not required. $\mathrm{As}_{\mathrm{scCO}}$ is a non-polar solvent, no dispersing agent is needed when polyester is dyed. However, high-pressure equipment is required for the purpose involving high investment.

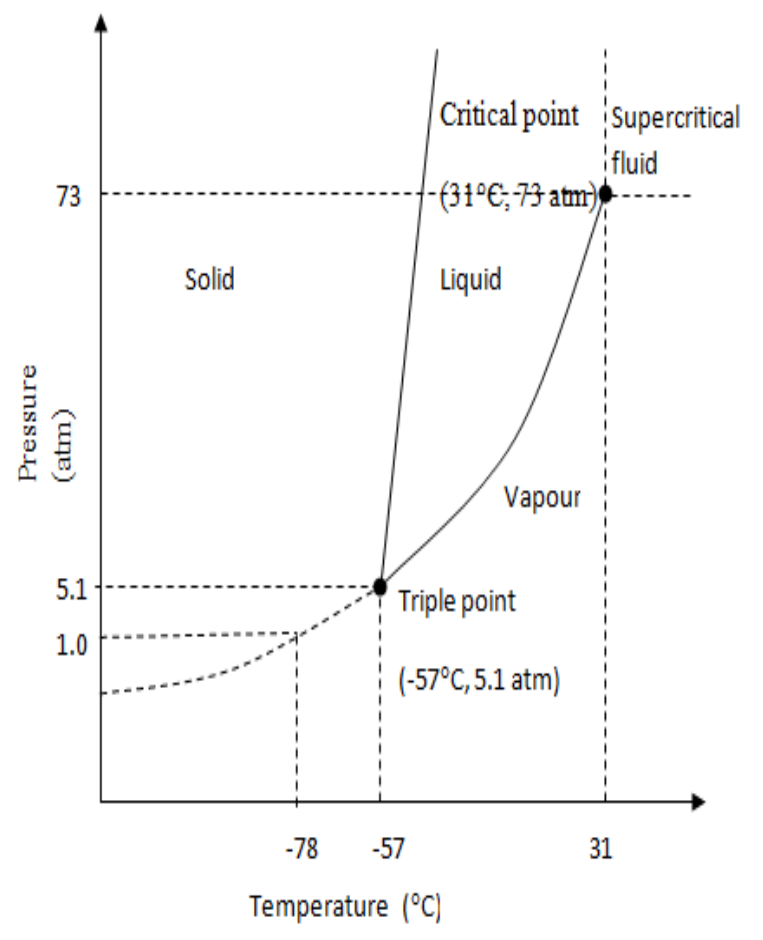

Figure 5 Various Physical States of Carbon Dioxide.

\section{Greener finishing agents}

The release of formaldehyde vapour is a problem with the most widely used cross-linking agents in textile finishing, N-methylol agents or N-methylolamides. A number of formaldehyde-free crosslinking agents have been developed.

\section{Greener effluent treatment}

Chemists have recently created enzyme-like catalysts called tetra-amido macrocyclic ligand activators (TAMLs) that can destroy stubborn pollutants by accelerating cleansing reactions with hydrogen peroxide. Synthetic TAMLs, peroxide-activators (with iron as the central metal atom) decompose peroxide on timescales ranging from minutes to hours. The molecular weight of a TAML is about 500daltons (a dalton is equal to one twelfth the mass of carbon 12), whereas the weight of horse-radish peroxidase, a relatively small enzyme, is about 40,000 daltons. The tiny TAML activators are easier and cheaper to make, and much more versatile in their reactivity, than their natural counterparts.

At the centre of each TAML (Figure 6) Hoy \& Workman ${ }^{30}$ is an iron atom bonded to four nitrogen atoms; at the edge is carbon rings linked to form a big outer ring called a macro cycle. This linking system acts as a firewall, enabling the molecule to endure the violent reactions it triggers. In its solid state, the TAML has one water molecule called ligands attached to the iron atom. When a TAML dissolves in water, another water molecule connects to the catalyst. If hydrogen peroxide $\left(\mathrm{H}_{2} \mathrm{O}_{2}\right)$ present in the solution, it can easily replace one of the loosely attached water ligands. The peroxide ligand then discards both its hydrogen atoms and one oxygen atom in the form of a water molecule, leaving one oxygen atom attached to the iron. The oxygen pulls electrons farther away from the iron atom, turning the TAML into a reactive intermediate.

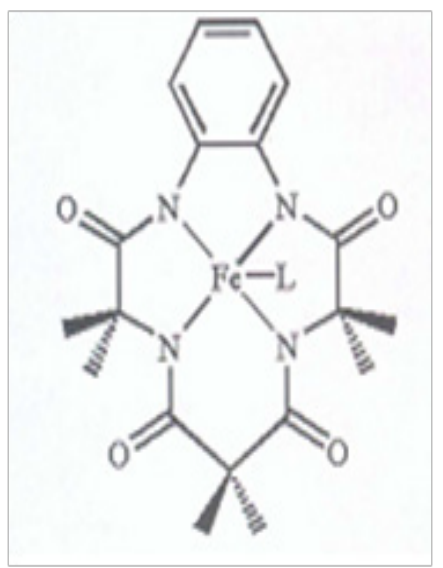

Figure 6 Tetra-amido macro cyclic ligand activators (TAMLs).

Pentachlorophenols (PCPs) and trichlorophenols (TCPs) are known carcinogens. They persist in the environment as natural microbes cannot break them down. Collins ${ }^{1}$ showed that Fe-TAML/ hydrogen peroxide catalytic system is capable oxidative breaking down PCPs and TCPs into environmentally benign products.

\section{Eco-label}

According to Global Eco-labeling Network, an Eco-label is 'a label which identifies overall environmental preference of a product within a product category based on life cycle consideration'. This label is awarded by an impartial third party to products that meet established environmental leadership criteria. Eco-labels are very important to the development of a sustainable and a credible textile industry Moore \& Wentz. ${ }^{31}$

Eco-labels are of two categories - Governmental and commercial. The examples of Government administered eco-labels (country) are Blue Angel(Germany), Green Seal(USA), Eco-mark(Japan, India), European Flower(EU), NF Environment(France). A few commercial eco-labels are Oeko-Tex Standard 100 (Austria/Germany), GuT(Carpet, Germany), GuW(Furnishing, Germany) and Global Organic Textile Standard (GOTS). ${ }^{32}$

\section{Conclusion and future trends}

There will be increasing pressures on suppliers and retailers to source their goods ethically and with minimal adverse effects on the environment. These demands arise not only from consumers but from 
many national and international organizations whose aim is to raise public awareness of such issues.

As globalization of the wet processing industry continues, it is clear that the textile industry can continue to 'green' its processes and chemistry. The communities in which these industries relocate can work together to provide an optimum situation where industrial growth and prosperity can be maximized without a negative impact on local water quality. The best news is that it can work, not only by using sophisticated toxicological and chemical technology, but also by dialogue and commonality of purpose.

The chemists need to co-operate with other disciplines. It is important that chemists and engineers work together to develop new sustainable processes. Only by combining the best ideas from both areas will the required technological leaps be made.

The application of the principles of green chemistry and other aspects of clean technology will increasingly lead to more environmentally compatible manufacturing systems.

\section{Acknowledgments}

None.

\section{Conflict of interest}

Author declares there is no conflict of interest in publishing the aticle.

\section{References}

1. Collins TJ, Walter C. Little green molecules. Sci Am. 2006;294(3):83-88.

2. Webster. Webster's New Millennium Dictionary of English, Preview Edition (v 0.9.7). LLC, USA: Lexico Publishing Group; 2006.

3. Goel PK. Water Pollution, Causes, Effects and Control. 2nd ed. New Age International, New Delhi, India; 2006. p. 1-432.

4. Landage SM. Colourage. 2009. p. 51-58.

5. Panov VP, Zykova IV, Chekrenev SA. Heavy metals: The industry and environmental protection. Fibre Chemistry. 2008;40(3):241-245.

6. Phipps DA. Effect of Heavy Metal Pollution on Plants. In: Lepp NW, editor. London: Applied Science Publishers; 1981. p. 1-54.

7. Bernstein JA, Alexis $\mathrm{N}$, Bacchus $\mathrm{H}$, et al. The health of effects of non industrial indoor air pollution. $J$ Allergy \& Clinical Immunol. 2008;121(3):585-591.

8. EHSC (Environment, Health and Safety Committee). Royal Society of Chemistry: Legal and ethical responsibilities for environmental protection. London; 2002. p. 1-6.

9. Dawson TL. It must be green: meeting society's environmental concerns. Coloration Tech. 2008;124(2):67-78.

10. Defining Life Cycle Assessment (LCA). EPA (US Environmental Protection Agency), USA; 2010.
11. Albrecht W, Reintjes M, Wulfhorst B. Chem Fibers Int. 1997;47:298.

12. Matus KJM, Anastas PT, Clark WC, et al. Overcoming the Challenges to the Implementation of Green Chemistry. Center for International Development, Harvard University, USA; 2007. p. 155.

13. Barnes. Life Cycle Inventory for Cotton, Cotton Incorporated. 2009.

14. Clark JH. Green Separation Processes. In: Afonso CAM, Crespo JG, editors. WILEY-VCH Verlag, Weinheim, Germany; 2005.

15. Matus KJM, Anastas PT, Clark WC, et al. Overcoming the Challenges to the Implementation of Green Chemistry. Center for International Development, Harvard University, USA; 2007. p. 155.

16. Poliakoff M, Licence P. Sustainable technology: Green chemistry. Nature. 2007;450(7171):810-812.

17. Trost BM. Atom economy- A challenge for organic synthesis: homogeneous catalysis leads the way. Angew Chem Int Ed Engl. 1995;34(3):259-281.

18. Sheldon Roger A. Methods and Reagents for Green Chemistry: an Introduction. In: Tundo P, Perosa A, Zecchini F, editors. New Jersey: John Wiley \& Sons; 2007. p. 191.

19. Ali Mohammad, Inamuddin. Green solvent properties and applications in chemistry. 1st ed. Springer; 2011.

20. Manahan SE. Fundamentals of Environmental Chemistry. Boca Raton, Florida: CRC Press; 2001.

21. Jessop PG. Canadian Chemical News. 2007;59(2):16-18.

22. Teli MD. Textile coloration industry in India. Color Technol. 2008;124(1):1-13.

23. Oecotextiles. Environmental Hazards of the Textile Industry, Business Week. 2005.

24. Reddy N, Yang Y. Properties and potential applications of natural cellulose fibers from cornhusks. Green Chem. 2005;7:190-195.

25. Grose L. Sustainable textiles: life cycle and environmental impact. In: Blackburn RS, editor. Cambridge: Woodhead Publisher; 2009. p. 33-60.

26. Handling Dyes Safely. ETAD, Washington, USA; 1997.

27. Hawley JM. Recycling in Textiles. In: Wang Y, editor. Cambridge: Wood head; 2006. p. 7-24.

28. Park J. Instrumental colour formulation, a practical guide. Nrth Carol, New York, USA; 1993.

29. Park J, Shore J. Practical Dyeing. Society of Dyers and Colourists. Bradford, UK; 2004. p. 563.

30. Hoy ZD, Workman J. Oxidative Destruction of Phthalate Esters with an Iron-Tetra amido Macro cyclic Ligand/ Hydrogen Peroxide Catalytic System. D Space Foundation. 2014.

31. Moore SB, Wentz M. Sustainable textiles: life cycle and environmental impact. In: Blackburn RS, editor. Cambridge: Wood head; 2009. p. 214-229.

32. Roy Choudhury AK. Green Chemistry and the Textile industry. Textile Progress. 2013;45(1):3-143. 